\title{
The Principles of Selecting and Structuring the Syllabus of Foreign Language Teaching Aimed at Developing the Students Research Competence
}

\author{
Olga V. Lopatina ${ }^{1}$, Olga G. Maksimova ${ }^{2}$, Tamara V. Talanova ${ }^{3}$, Lyutsiya G. Khismatullina ${ }^{4}$, Guzel R. \\ Fassakhova $^{5}$, Timur A. Shaikhullin ${ }^{6} \&$ Natalya V. Makovey $^{7}$ \\ ${ }^{1}$ Kazan National Research Technical University named after A. N. Tupolev, Kazan, Russia \\ ${ }^{2}$ Chuvash State Pedagogical University named after I. Y. Yakovlev, Cheboksary, Russia \\ ${ }^{3}$ Chuvash State University named after I. N. Ulyanov, Cheboksary, Russia \\ ${ }^{4}$ Kazan Federal University, Kazan, Russia \\ ${ }^{5}$ Kazan State Agrarian University, Kazan, Russia \\ ${ }^{6}$ Russian Islamic Institute, Kazan, Russia \\ ${ }^{7}$ Amur State University, Blagoveschensk, Russia \\ Correspondence: Olga Vladimirovna Lopatina, Kazan National Research Technical University named after A. \\ N. Tupolev, K. Marks Street 10, Kazan, Tatarstan, 420111, Kazan, Russia. E-mail: alfkazan@mail.ru
}

Received: January 17, 2015 Accepted: January 29, 2015 Online Published: February 26, 2015

doi:10.5539/res.v7n3p319 URL: http://dx.doi.org/10.5539/res.v7n3p319

\begin{abstract}
The essence of the development of the students research competence in the process of learning a foreign language is to acquire knowledge, skills and work methods allowing students to take the position of a researcher capable both to carry out and present the results of the research in the international language that contributes to unlocking their full intellectual potential in the future professional activity. The methodological basis for solving this problem has become the modular competence-forming, research and integrative approaches. According to these approaches the article discusses the nature and the content of the principles of selection and structuring the syllabus of foreign language teaching aimed at creating the students research competence: the principle of integration, the principle of poly-logic cognition, a problematic principle, the principle of concentrism and the principle of mediation activities by means of learning a foreign language. The article submissions present both theoretical and practical value for the teachers of "Foreign Language course" as well as for the future teachers.
\end{abstract}

Keywords: principles, selecting and structuring, syllabus, foreign language, teaching, research competence, students

\section{Introduction}

\subsection{Thematic Justification}

At present time, the system of foreign language education as a part of the whole educational system undergoes radical changes due to the variety of interrelated factors influencing its change. According to N. D. Galskova, the factors causing the change of requirements to the system, its nature and the components together with the goal-setting include socio-economic and political, socio-cultural, educational, pedagogic and individual factors. The priority should be given to the socio-economic factors that determine the social order in relation to foreign language education of its citizens and its goals (Galskova, 2003; Mrathuzina et al., 2015; Fayzullina \& Mukhametzyanova-Duggal, 2015).

Nowadays the impact of such factors as the development of interstate integration and national socio-economic reforms have resulted in a significant increase of educational and self-educational functions in learning foreign languages in higher education, their professional significance in the labor market, involvement of the fairly large number of people into direct and indirect communication (e.g., the Internet) which resulted in growing demand for the international languages learning and further updating of its syllabus (Shaidullina et al., 2015: Ivanov et al., 2015; Sakhieva et al., 2015). 
The transnational corporations, international companies and joint ventures the number of which has been growing steadily in recent years require from all employees of economics the obligatory fluency in a foreign language. (Fayzullina, 2007; Nikiforov \& Fayzullina, 2007). The variety of conditions of using a foreign language in educational, professional and research activities is conditioned by several factors:

Firstly, the different sectors of the economy have an impact on professional communication, primarily —on its subject. Their specificity is reflected in the areas of training of the future professionals and the university specialization (Polyakova, 2008).

Secondly, according to the purpose of professional activity and the tasks solved by the experts there are various professional activities that determiney the specific use of a foreign language. So, for example, the use of foreign terminology by the experts in economics working in the field of science and the economists working in the field of labor and management can be essentially different.

Third, in recent years the Russian market have received a great number of foreign manufacturers, joint ventures and enterprises, multinational corporations the international team of which increases the areas of a foreign language application and professional communication in a foreign language more or less comes around.

Fourth, the direct professional duties impose a significant impact on the use of a foreign language in professional activities. Working for the same joint venture requires from the top-level and mid-tier economists different levels of the professional foreign language competence.

Fifth, in the field of higher education there are new conditions for foreign language communication due to the integration of international education systems particularly in the framework of the Bologna process. The necessity for foreign language skills is highly demanded by the lecturers participating in international projects as well as the students, graduates and postgraduates who intend to study abroad (Polyakova, 2008).

Sixth, a specialist needs a foreign language for purely translational activity, as the employers prefer to hire as a translator an economist who shows foreign language competency.

The variety of professional conditions of foreign language application leads to the diversification of the needs of today's specialists in economics in learning a foreign language.

\subsection{Literature Review}

An innovative approach to teaching a foreign language to the future economists involves, first, providing its continuity due to the periodic change of working conditions, and secondly, its diversification in accordance with a variety of professional needs of the economists.

Designing an integrated system of continuous professional foreign language training answering the call of national and international trends in the development of higher education should consider the variety of labor market requirements and provide students with freedom to choose the educational trajectories.

We support N. D. Galskova's opinion that foreign language training as a part of economic education is directed to meet the urgent needs of the future economist in learning a foreign language, and its aim is to develop foreign language communicative competence as part of the professional competence of an expert in the economic sphere This objective is considered as an integrative unity having "access" to the personality of the learner, his willingness, ability and personal qualities that enable him to carry out various kinds of verbal and cogitative activity in the conditions of social interaction with other linguo-ethnic societies and their culture, a different linguistic image of the world (Galskova, 2003). We also believe that this integrative purpose is manifested in the relationship and interdependence of the three aspects: the pragmatic (or practical), cognitive and pedagogic. The first pragmatic aspect is associated with the formation of the communicative competence of the student, and the cognitive one - with the use of a foreign language as a tool for learning different Linguocultures and, therefore, as a means of developing intercultural competence and personality in general. The pedagogic aspect is designed to determine the mode of "extralinguistic existence" of a bi /multi-cultural linguistic identity. By "extralinguistic" qualities of a personality able to communicate in the situations of intercultural interaction we understand independence, activity, empathy. The empathy supposes an experience of emotional and evaluative attitudes of a person toward linguo-ethnocultural interaction and its subjects. Some authors associate empathy with the manifestation of tolerance to a different way of thinking, to another position of the communication partner showing the ability and desire to see and understand the differences and commonalities in the cultures, in their world perception and eagerness to perceive a different lifestyle and understand it.

The main objectives of foreign language teaching at the present stage are the following:

- Teaching the everyday speech and special professional language for active use of a foreign language, both in 
everyday and professional communication;

- The formation and development of the students' intercultural communicative competence, the level of which at certain stages of language training allows to use the foreign language in professional work and in self-educational activity;

- The study of a foreign language as a cultural and social phenomena, increasing thereby the intellectual and cultural level of the students, mastering the ethical norms of communication;

- The development of the students' ability to identity in their activity and communication, self-modification, the development of the ability to think, speak, act, and in the end-self-develop, self-improve and fulfill themselves (Approximate program of discipline "Foreign Language" the federal component, 2000).

To implement the abovementioned goals and objectives of foreign language teaching T. Polyakova considers the following aspects:

1) The functional focus to meet various needs of a modern specialist in learning a foreign language;

2) The diversification of the training profiles depending on the enterprise specialty and diversified levels of foreign language proficiency according to the type of professional activity;

3) The appropriate structure that provides invariant and variative parts, combines both university and post-graduate courses of a foreign language, includes both compulsory and elective educational programs in a foreign language and suggests the possibility of including an unlimited number of educational programs depending on the emerging needs;

4) Flexibility allowing to implement its different versions at the level of the university, faculty, specialty, at the level of an individual;

5) The continuity providing the graduates and students with the opportunity to further improve the achieved level of foreign language competence (Polyakova, 2008).

Teaching to communicate in a foreign language is carried out within its functions: cognitive (verbal communication, written communication through the book, letters, etc.); regulatory (communication regulates the behavior of people, encourages them to interact); axiological (learning to communicate shapes the person's worldview, his own standpoint); etiquette (along with cognitive and axiological functions the students shape their verbal behavior, which in turn is the key to mutual understanding between people). Therefore, while determining both the syllabus and the teaching strategies mastering all the functions of communication ensures the integrated implementation of practical, educational and evolutive potential of the discipline (Borisova \& Melikhova, 1989). We consider that the strategic planning process of learning a foreign language can solve specific problems of communication in a foreign language within academic and professional communication environment and provide the students with the opportunity to arrange their learning activities in a foreign language linking it with the professional goals (Grigoryeva et al., 2015).

In the course of the research we found confirmation that such a vision of the educational prospects by the language teachers and consequently by the students of economics bring obvious results when the international collaborative studies in the process of academic activities grow up to the formed system of meeting the person's professional needs. In our opinion under such circumstances a foreign language proficiency becomes an important factor in future economists professional identity (Lopatina et al., 2015).

Therefore, the most important task of providing multicultural language environment at the university involves combining the efforts of specialists in different areas of expertise to develop a conceptually new paradigm of vocational education basing on a symbiotic formation of several competencies, including a research competence. To achieve these goals it seems reasonable to arrange at the universities the international interdisciplinary laboratories including those for intensive mastering the foreign languages; to open a center of cultural heritage; a center of vocational guidance with a data bank of the international contacts for employment of the university graduates and consulting help such as tutoring for documentation design, compiling a professional portfolio to comply with the socio-cultural peculiarities of the language of the paper (Slesarenko, 2008).

The study has found that such organization of a foreign language training of the future economists promotes to the development of cross-cultural communication skills in academic environment, develops the abilities to carry out international educational projects, contacts, skills of independent and team work in a reference system of the foreign language they study, that is developing their research competence, as particularly this one becomes an objective necessity and legitimate feature of the process of improving vocational education in the new education policy. 


\section{Methodological Framework}

The methodological basis for identifying the principles of selection and structuring the syllabus of teaching a foreign language aimed at the development of the students' research competence have become the modular competence-based, integrative and research approaches.

\subsection{Modular Competence-Based Approach}

Since the basic principle of structuring the syllabus of foreign language teaching is the principle of modularity, we found it appropriate to combine the conceptual basis of the competency building approach with the principle of modular structuring of the syllabus as a method of developing the research competence and to determine the general provisions of modular competence-based approach.

We believe the essence of the modular organization of the system of profession-oriented education based on learning a foreign language can be stated like this: in order to satisfy the professional needs the future specialist should achieve a basic level of communicative ability to carry on within social and socio-cultural communication The study has found that in this case through the basic, compulsory academic modules it is possible to form the basis for linguistic and socio-cultural competencies.

Then we proposed a set of compulsory-elective modules of the general industry topics. The professional syllabus of the training modules continues to borrow the linguistic and socio-cultural content from the general course of a foreign language.

The further specialization of the students according to their professional needs and interests has been performed through sector-specific compulsory and elective modules.

It was important that the syllabus of the foreign language teaching that was effective within one specialty could be transferred to other activities while transferring the expertise and special foreign language means and methods of its expression into the student's store of knowledge, and then into the ability to creatively apply it in practice.

Modular competence-based approach to the problem of formation of the students research competence in the process of learning a foreign language, in turn, reflects the axiological attitudes of the future economist; the systems organization and self-organization of the educational process; the teachers and students interaction in the academic process. Teaching a foreign language within the modular competence-based approach allows to provide the variability of the educational process; personality-centered focus through the relevant forms, methods and techniques of instruction; the assessment of the levels of competencies development and quality assessment (qualified or low-skilled); the development of professional competencies of the future specialists in economics in the process of learning a foreign language.

\subsection{The Integrative Approach}

As part of the integrated approach we have found it essential to create the interdisciplinary connections in learning a foreign language, which has become a compulsory part of the training and education system for the students of economics and performed the system-forming role in the selection and structuring of the foreign language course content. Representing the primary didactic means of interdisciplinary integration, they provided the integration of training in a foreign language and training in general and special disciplines, as well as the development of professional identity of the specialist in economics.

In the selection of the foreign language syllabus we have taken into account the following possible integrative connections:

- Between the training courses of one cycle;

- Between the different training courses of the different cycles;

- Between the sections and the topics of the "Foreign Language" course;

- Between the sections and the themes of the different training courses;

- Between the knowledge and skills that comprise the content of the different disciplines (eg, linguistic knowledge and professional, verbal skills and professional communicative abilities; professional communicative skills and interdisciplinary skills);

- Between the types of activities (educational, research and professional).

Along with the interdisciplinary connections the selection of the syllabus of foreign language teaching in the system of higher economic education should reflect, as we have discovered in the course of the study, the generalized experience of applying knowledge in practice, as well as the skills of self-educational functions in 
the course of learning a foreign language. Therefore, we had to take into account at the regular updating of the theoretical knowledge on the professional specialty.

\subsection{The Research Approach}

As modern higher education is aimed at a new target—educating a creative personality of a specialist with high professional competence, the new values of education - the ability to feel confident in the profession and social environment, willingness to creativity, self-improvement and self-fulfillment. We have found it appropriate in the study to point out the research approach assuming the systematic updating of the subject syllabus, creating new concepts and developing a particular strategy of such upgrading.

Among the factors responsible for the development of the scientific research approach of the science-based pedagogy, A. O. Karpov identifies:

- Assimilation of the scientific knowledge in the society (introducing the scientific results into everyday life);

- The expansion of the science into profession which has created special demands to those characteristics of the worker which were brought up in school age;

- Rejuvenation of the professions associated with the science (Karpov, 2004).

Therefore, the selection and structuring the syllabus of foreign language teaching on the basis of the research approach has allowed us to point out the most important elements such as the acquisition and propaganda of the new knowledge, the participation of the scientists in designing the foreign language syllabus aimed at the development of intellectual potential of the students.

Within the research approach the common didactic methods has become the most important: the analysis and inferring the cause-and-effect relationship, comparing, generalization and specifying, hypothesizing, transferring knowledge into a new situation, the search for a new analogous solution to the problem, the evidence or disproof of a hypothesis, planning a research, presentation of the research results.

The research approach, a scientific idea or a concept offers a simultaneous and interrelated solution the three problems of the university life: the organization of the research activity at the university and departments, the development of teachers creativity and introducing scientific research into the academic process that contributes to the conceptual solution of the relation problems of the scientific research, methodological work of the departments and enhancing the students' cognitive activity.

\subsection{The Principles from the Scientific and Educational Literature}

The scientific and educational literature offers the following principles for selecting the syllabus of foreign language teaching, which should also be taken into account when shaping the research competence of the students in the process of learning a foreign language:

1) The principle of multiculturalism. According to this principle the selection of the educational material, as well as the arrangement of the educational process is carried out in such a way as to form a sense of respect to other people and nations. This principle specifies and amplifies the general principle of cultural conformity which is observed in the selection of the socio-cultural component of the foreign language syllabus and designing the language programs. The main focus of this principle is to familiarize students with the variety of other cultures (Dmitriev, 2000).

Considering the culture of the target language the students have the opportunity to familiarize themselves with similar information about the cultural diversity of their native country with every aspect of the study. This allows them to see not only the differences, but, that is more important, the similarities between the cultures (individually for every student) which in turn contributes to the expansion of social and cultural space outside the political boundaries of native country. Seeing the unity of people around the world on the basis of a common culture (in every aspect of identity: ethnic, social, professional, religious, etc.), also being aware of his own role, importance and responsibility for the global human processes, the students try to develop their global thinking (Dmitriev, 2000).

2) The principle of the native language. It is known that the native and foreign languages are autonomous systems. In the study of a foreign language these systems establish various connections between each other which, on the one hand, is manifested in the processes of comparison and creating the system of equivalents (positive transfer) and, on the other hand, can cause cross-language interference having a negative impact on understanding the information. While selecting the syllabus it was reflected in the ways of semantization of the language material and the exercises designed to prevent possible interference and absorption of those phenomena of a foreign language which significantly differ from the possible analogues in the native language or even those 
which do not exist in the native language. As for the speech exercises representing the acts of natural communication in a foreign language the native language there has not been used.

3) The principle of professional and communicative focus involving the selection of the foreign language syllabus as close to the conditions of authentic professional communication as possible (Sheylz, 1995).

4) The functional principle, according to which the basis of the selected educational texts should belong to a particular speech genre which allows for the formation of various speaking and writing skills. This principle is extremely important, because it turned out to be very useful in creating a typology of the relevant linguisticallydidactic texts of various genres as the basis for their selection and arrangement in stages and in accordance with the sub-goals offering the most efficient way to solve the problem of students' training for different types of professional speech activity in a foreign language.

5) The principle of social demand which means that the syllabus of any subject is determined primarily with the targets that the society sets at every stage of its socio-economic, scientific, technological and cultural development and, consequently, this selection should meet the needs of society (Mukhametzyanova, 2008).

6) The principle of integrating the informative and process components of education means that while designing the syllabus one should take into account the technology of its transferring and assimilation.

\section{Results and Discussions}

\subsection{The Objectives and Tasks of the Development of the Students Research Competence in the Process of Learning a Foreign Language}

The objective of developing the students' research competence in the process of learning a foreign language is the formation of a sustainable interest in the process of research activities in a foreign language. We have established the following objectives: the formation of intercultural communicative competence; forming ability of the students to self-determination in research and communication activities; develop the ability to think, speak a foreign language, etc.

\subsection{The Principles of Selection and Designing the Syllabus of Foreign Language Teaching}

In accordance with the abovementioned approaches, goals and objectives of developing the students' research competence in the process of learning a foreign language we have identified the following principles of designing the syllabus of foreign language teaching :

- The principle of integration involving interdisciplinary, integrative cross-thematic connections and integration activities (educational, learning, research and professional) in hierarchic order of complex, integrated and particular didactic goals. According to this principle the selection of educational material was carried out by studying the key components of the logical structure of academic disciplines - the fundamentals of science, engineering, technology, production, labor functions of an economics specialist and objects of labor, etc. All these contributed, in turn, to the professionally-focused teaching of a foreign language;

- The principle of poly-logic cognition that presupposes the existence of not only professionally-oriented educational material, but also philosophical, sociological, economic, psychological one required for the professional activity of the future economist to choose the correct behavioral strategies to ensure the effectiveness of his cross-cultural communication;

- The principle of concentrism providing the selection of a foreign language syllabus which provides multiple reference to those functions of language that have already been studied with gradual increasing and widening of the language material;

- The problematic principle suggests including into the syllabus the challenges that can activate the students' cognitive activity. This principle does not exclude the necessity in informing-explanatory methods of presenting a new material, but as we are aware of all the advantages of problem-based learning, in all cases where possible and appropriate we applied the tasks of problematic nature;

- The principle of the activities mediation with the help of a foreign language suggests such a selection of the foreign language syllabus where a foreign language is not the objective for itself but a research tool (for example, the students participation in the international grants). Such syllabus organization treats a foreign language as a means of acquiring new knowledge and other skills by yourself.

However, the principles of selecting the foreign language syllabus aimed at establishing the students' research competence we identified have appeared insufficient in the formation of the communicative and professional competence of the students. 
The interdependence of the principles and their focus towards a common goal allows to combine them into a didactic system where underestimation of any of them violates its integrity.

\section{Conclusions}

Therefore, the essence of the development of the students research competence in the process of learning a foreign language is to acquire knowledge, skills and work methods allowing students to take the position of a researcher capable to carry out and present the results of the research in the international language that facilitates the unlocking of their intellectual potential in the future professional activities.

Among the principles of selection and structuring the syllabus of foreign language teaching aimed at creating the students' research competence we have highlighted: the principle of integration, the principle of poly-logic cognition, the problematic principle, the concentricism principle and the principle of activities mediation with the help of a foreign language.

\section{References}

Borisova T. B., \& Melikhova, G. V. (1989). A new conceptual approach to the problem of foreign language teaching. Foreign languages at school, 4, 50-56.

Dmitriev, G. D. (2000). Multiculturalism as a didactic principle. Pedagogy, 10, 12-15.

Galskova, N. D. (2003). Modern methods of teaching foreign languages: A guide for teachers (p. 192). Moscow.

Grigoryeva, E. V., Leyfa, I. I., Yatsevich, L. P., Demyanenko, M. A., Makovey, N. V., Pavlushkina, T. V., \& Masalimova, A. R. (2015). Designing a Structure of the Modular Competence-Based Curriculum and Technologies for Its Implementation into Higher Vocational Institutions. Review of European Studies, 7(1), 123-129,

Ivanov, V. G., Shaidullina, A. R., Drovnikov, A. S., Yakovlev, S. A., \& Masalimova, A. R. (2015). Regional Experience of Students' Innovative and Entrepreneurial Competence Forming. Asian Social Science, 11(1), $35-40$.

Fayzullina, A. R. (2007). Immigration policy in modern Russia (federal and regional aspects) (Thesis for the degree of Candidate of Political Science). Ufa: Bashkir State University.

Fayzullina, A. R., \& Mukhametzyanova-Duggal, R. M. (2015). Multi-Confessional Societies in Russia and India: Models of Relations between the State and Religious Associations. Review of European Studies, 7(1), 12-17.

Karpov, A. O. (2004). Science education in the modern school. Education, 9, 47-56.

Mrathuzina, G. F., Fayzullina, A .R., \& Saglam, F. A. (2015) Substantive, Methodological and Organizational Discourse in Oriental History Learning at School and University. Review of European Studies, 7(1), 57-62.

Mukhametzyanova, G. V. (2008). Professional education: A systematic approach to the problem (p. 608). Kazan.

Nikiforov, Y. N., \& Fayzullina, A. R., (2007) Migration processes in the Republic of Bashkortostan Bulletin of the University of Perm. Politics Series, 1, 240-244.

Polyakova, T. (2008). Tradition and Innovation in foreign language training of an engineer. Higher education in Russia, 10, 55-62.

Sakhieva, R. G., Khairullina, E. R., Khisamiyeva, L. G., Valeyeva, N. S., Masalimova, A .R., \& Zakirova, V. G. (2015). The Syllabus of the Regional Component of Professionally Motivational Education Developed for the Students Specializing in Tourism. Asian Social Science, 11(2), 246-251.

Shaidullina, A. R., Krylov, D. A., Sadovaya, V. V., Yunusova, G. R., Glebov, S. O., Masalimova, A. R., \& Korshunova, I. V. (2015). Model of Vocational School, High School and Manufacture Integration in the Regional System of Professional Education. Review of European Studies, 7(1), 63-67.

Sheylz, D. (1995). Communication skills in teaching modern languages (p. 349). Council for Cultural Co-operation. The project No. 12 "Learning and teaching modern languages for communication", Council of Europe Press.

Slesarenko I. (2008). The organization of language training engineer at the University of innovative type. Higher education in Russia, 7, 105-108. 


\section{Copyrights}

Copyright for this article is retained by the author(s), with first publication rights granted to the journal. This is an open-access article distributed under the terms and conditions of the Creative Commons Attribution license (http://creativecommons.org/licenses/by/3.0/). 